\title{
História e produção da escrita entre os Xakriabá e os Pataxoop de Minas Gerais
}

\author{
History and writing production among the Xakriabá and \\ the Pataxoop of Minas Gerais
}

Ana Maria R. Gomes ${ }^{1}$

Célia Nunes Corrêa ${ }^{1}$

Shirley Aparecida de Miranda ${ }^{1}$

DOI: http://dx.doi.org/10.20435/tellus.vi43.697

Resumo: Neste artigo, analisamos processos recentes de produção de materiais escritos entre os Xakriabá e os Pataxoop (MG), cujos produtos assumiram diferentes formatos, buscando trazer aspectos centrais que delineiam as características do conteúdo e da forma final do produto editorial. Ambos são povos indígenas que têm o português como língua materna. O caso dos Pataxoop ilustra uma reelaboração original da escrita em associação com outras formas expressivas, como o canto e o desenho. O caso dos Xakriabá revela o uso da escrita inserido em processo de elaboração sobre a história de luta, com um procedimento de autoria coletiva negociada no qual a memória ingressa num exercício cruzado de sentido acadêmico e político e com repercussões epistemológicas.

Palavras-chave: educação indígena; escrita indígena; Xakriabá; Pataxó/ Pataxoop.

Abstract: This paper analyzes recent processes of production of written materials among the Xakriabá and the Pataxoop (MG), whose products have taken different formats, seeking to stress central aspects that outline the characteristics of the content and the final form of the editorial product. Both are indigenous peoples who have Portuguese as their mother tongue. The case of the Pataxoop illustrates an original reworking of writing in association with other expressive forms, such as singing and drawing. The case of the Xakriabá reveals the use of writing inserted in the process of elaboration on the history of struggle, with a negotiated collective authorship procedure in which memory enters into a cross exercise of academic and political meaning and with epistemological implications.

Keywords: indigenous education; indigenous writing; Xakriabá; Pataxó/ Pataxoop.

${ }^{1}$ Universidade Federal de Minas Gerais (UFMG), Belo Horizonte, Minas Gerais, Brasil. 


\section{INTRODUÇÃO}

As produções de materiais em línguas indígenas e, mais amplamente, de materiais de autoria indígena, tem crescido significativamente ao longo das últimas duas décadas no Brasil, em boa parte, mas não exclusivamente, estimulados pelas propostas de educação escolar indígena (cf. LIMA, 2012). As políticas de promoção de materiais produzidos pelos próprios professores indígenas, objetivando atender ao que seria considerado as demandas de suas escolas, embora tenham sido descontínuas e imprecisas na maior parte do período, contribuíram para que se abrisse um cenário capaz de acolher, em muitos casos, processos e procedimentos que já vinham ocorrendo nas comunidades e, de uma certa forma, articulá-los à produção autoral escrita.

Neste artigo, analisamos processos recentes que resultaram em materiais em diferentes formatos, buscando recuperar aspectos históricos a partir dos quais se torna possível a concretização dessas produções, aspectos que, de forma decisiva, delineiam muitas de suas características quanto ao conteúdo e à forma final que assume o produto editorial. Trata-se, em ambos os casos apresentados, de povos indígenas que têm o português como língua materna, com processos diferentes de reconstrução da língua indígena ancestral, e com percursos singulares de apropriação da escrita em português: os Xakriabá e os Pataxoop de Muã Mimatxi, ambos em Minas Gerais².

A perspectiva que orienta a apresentação dos dois casos busca evitar a simplificação de análises que situam esses processos e produtos como exclusivamente decorrentes do possível impulso que as políticas e propostas de educação escolar indígena vêm promovendo. Busca-se constituir um lugar de enunciação que situa tais ações no curso das interações desses povos com a sociedade mais ampla e especialmente com as agências de Estado, de forma a assumir e conduzir esses processos em sintonia e na direção de suas lutas e demandas, assim como forma de interagir e responder a processos internos, inerentes à história de cada povo e/ou comunidade. Essa é a posição apresentada na dissertação de mestrado recentemente defendida por Célia Nunes Corrêa (2018), jovem liderança entre

2 Em acordo com a comunidade referida neste artigo, que se identifica como Pataxoop, usaremos essa grafia especialmente ao se referir às informações sobre esta específica comunidade. Em alguns casos, será usada a grafia Pataxó para se referir ao povo indígena no sentido mais amplo. 
os Xakriabá, em que ela procura expressar os vários tempos desse processo e o "amansamento da escola" conduzido pelo seu povo.

Tal posicionamento decorre em grande parte da experiência de mais de 20 anos de acompanhamento dos Xakriabá e dos Pataxoop em uma miríade de ações, iniciativas e projetos de ensino, de pesquisa e de extensão, conduzidos por diferentes pesquisadores e profissionais junto a esses povos e suas comunidades ${ }^{3}$. Esse acompanhamento - que veio a se constituir no tempo como uma forma consolidada de parceria entre esses povos e as equipes da UFMG - vem revelando de forma incisiva que as decisões e reações que as comunidades colocam em ato quando são interpeladas pelas propostas oriundas das políticas públicas, ou de outras fontes, como os editais voltados para atividades de produção cultural, não são nunca uma resposta linear a essas proposições. Ao contrário, são as comunidades que pautam em modo bastante incisivo, ainda que não imediatamente explícito, a direção que tais possíveis ações podem assumir, mesmo operando em modo tático dentro de estratégias que nem sempre são as por eles desejadas e ensejadas em suas lutas.

Por outro lado, ao lidar com a escrita - e ainda mais intensamente, com a escrita em língua portuguesa - não tem como não se levar em consideração as dinâmicas de colonização e catequização que marcam a experiência desses povos ${ }^{4}$. O uso da escrita foi desde sempre um elemento de supressão do discurso próprio dos povos indígenas (RIVERA CUSICANQUI, 2010; 2015), quer pela negação do uso de suas línguas, ação deliberada que caracterizava a organização dos aldeamentos a que foram submetidos, quer pela hierarquização do registro escrito alfabético em detrimento de outras formas de escrita e ou mesmo as formas gráficas pictóricas.

3 Referimos aqui parcialmente os grandes projetos/programas como o curso de Formação Intercultural para Educadores Indígenas (FIEI/FAE/UFMG) desde 2006; o desenvolvimento de atividades em 4 subprojetos temáticos no Observatório da Educação Escolar Indígena (OEEI/ UFMG) financiado pela CAPES/MEC entre 2009 e 2016; as atividades do grupo de pesquisa em Educação Indígena da FaE/UFMG desde 1999, atualmente Observatório da Educação Intercultural Indígena, registrado no CNPq; e em particular o projeto de extensão Saberes Indígenas na Escola (SIE) a partir de 2013, que contou com financiamento da Secadi/MEC e será mais detalhado nessa sede; além de iniciativas das próprias associações indígenas em parceria ou não com pesquisadores e outros profissionais.

4 Ver os trabalhos pioneiros de Ana Flavia M. Santos para os Xakriabá (1997); e de Maria do Rosário Carvalho para os Pataxó (1977). Ver Santos (2013), sobre os povos indígenas das Gerais. 
É, portanto, nessa tensão entre ações e intenções que por vezes se revelam opostas, divergentes, em mundos que são copresentes e de alguma forma articulados entre si (cf. DE LA CADENA, 2015; BLASER, DE LA CADENA, 2018), que buscamos produzir os registros que aqui apresentamos. Eles vão se configurando a partir de um emaranhado de questões de toda ordem, que não somente aquelas que emergem de forma mais recorrente e explicitamente declarada na evolução das atividades relacionadas com escrita e com o processo editorial, até a culminância na definição de um material final com características específicas. Procuramos assim revelar o quanto esse "produto" é somente a ponta, ou a emergência mais visível de um processo bem mais denso e profundo, cuja significação responde também pela possibilidade de sua mais efetiva fruição no seio da comunidade que gerou e promoveu esse "produto editorial".

Os casos aqui assumidos para ilustrar esses percursos têm características que nos chamaram a atenção pela maneira singular em que se deu a relação com o exercício da escrita. O primeiro deles - a produção dos Têhêy de D. Liça Pataxoop - nos traz a possibilidade de uma resistência ou recusa da escrita, uma vez que a autora, que é professora de "Uso do Território" e "Práticas Culturais" na escola de sua aldeia, optou por produzir graficamente de forma sistemática e comunicar somente por desenhos. A continuidade no tempo e a expressividade da produção em seu conjunto (embora não finita) geraram uma linguagem pictórica e gráfica específica, sistemática e organicamente inserida nas atividades da escola, na qual D. Liça atua com crianças e adolescentes de todas as idades. O outro caso, do livro "O tempo passa e a história fica", de autoria coletiva entre os Xakriabá, revela, ao longo da dinâmica de produção de uma nova edição, um processo que aponta para formas de contingenciamento da escrita (ESCOBAR; GALVÃO; GOMES, 2017), submetendo-a a negociações e procedimentos que só encontram sua razão de ser no modo peculiar como os Xakriabá negociam internamente suas relações de autoridade e legitimidade política, na (re)produção de um livro que tem funcionado como referência circulante nas aldeias, e nas escolas, do registro da história deste povo.

Muito mais do que analisar os aspectos e dinâmicas estritamente linguísticos e textuais, vamos procurar descrever o modo como esses materiais são resultados do manejo que fazem seus autores do que a eles interessa produzir, a partir e em torno da proposta de um produto gráfico, ou seja de um livro. Esses 
dois temas - da imagem como instrumento gráfico que desafia a escrita, assumida em seu contexto de produção, ou ainda, trazendo consigo a história dessa produção entre os Pataxoop; e da elaboração da própria história através da produção de um livro-registro que assumiu um lugar emblemático entre os Xakriabá - adquirem maior força e significado ao serem abordados à luz do trabalho da socióloga boliviana de origem aymara, Silvia Rivera Cusicanqui, quando ela discute de forma veemente a necessidade de se descolonizar as práticas e os discursos (RIVERA CUSICANQUI, 2010) e propõe uma reorientação, ou retomada da história dos povos andinos através de uma sociologia da imagem (RIVERA CUSICANQUI, 2015). O exercício aqui foi então de retomar alguns aspectos das práticas de uso e produção da escrita que revelam dimensões significativas do modo de inserção destas práticas em percursos próprios de cada povo/comunidade. Assim como o exercício de promover uma "entrada no texto" das palavras de Célia Xakriabá e dos desenhos de D. Liça Pataxoop.

\section{PEGA FRUTA E PESCARIA DE CONHECIMENTO EM MUÃ MIMATXI}

Dentre os muitos materiais de autoria dos Pataxoop, escolhemos duas produções da aldeia Muã Mimatix (Itapecerica, MG): uma que já tem sua forma editorial definida há mais tempo como um livro de alfabetização, Pega Fruta, de autoria de Kanatyo e Siwê Pataxoop (2017). Sobre esse material, temos também a produção de uma monografia de conclusão do FIEl, de autoria de Saniwê Pataxó (BRAZ, 2016), na qual ele descreve e discute as práticas de alfabetização nos últimos dez anos, em diálogo não somente com os autores e professores, mas também explorando e registrando as experiências das crianças e jovens que foram alfabetizados com esse método. O segundo material é a publicação dos Têhêy de D. Liça Pataxoop, material que reúne mais de 70 pranchas desenhadas que ela, como "professora de cultura", desenvolveu e vem utilizando em suas atividades com alunos e alunas de todas as idades.

Muã Mimatxi, aldeia de pequeno porte, que conta hoje com pouco menos de 50 pessoas organizadas em torno de seus núcleos familiares, se instalou através de um processo progressivo, que tem sido caracterizado pela presença marcante das atividades da escola, seja em relação às crianças e adolescentes da própria aldeia, seja em relação ao acolhimento de professores e professoras com turmas 
de crianças e adolescentes das escolas da região para atividades de educação intercultural. Como afirmam sempre Kanatyo e Siwê Pataxoop, as atividades da escola não se separaram e nem se conduzem como algo distinto e diferente da vida da aldeia. Os materiais produzidos ao longo dos percursos que conduziram esse grupo ao atual local da aldeia trazem consigo a trajetória e a experiência acumulada que deu forma às práticas da escola, forma essa que buscou-se imprimir no material que veio a se constituir como livro. Na apresentação do Pega Fruta, é informado que se trata da prática educativa "Alfabetizar Cantando", o processo de alfabetização é desenvolvido a partir da letra de canções de autoria dos próprios Pataxoop. A apresentação nos fala ainda dos desenhos que compõem o livro, desenhos esses chamados de Têhêy de Pescaria de Conhecimento "que apresentam a história de cada música através da imagem. Através deles podemos estudar e pesquisar várias atividades com a leitura do desenho" (PATAXÓ; PATAXÓ, 2017, p. 7).

Uma outra característica da escola em Muã Mimatxi é a organização de um "calendário dos tempos da natureza e de nossa vivência de vida, que é um material de referência pedagógica" (PATAXÓ; PATAXÓ, 2017, p. 8). A partir dele, os professores buscam "trabalhar com novas práticas educativas, com metodologia própria inovadora, buscando desamarrar os nós de uma educação dominadora" (PATAXÓ; PATAXÓ, 2017, p. 8)

Os Têhêy vêm, portanto, de uma trajetória longa, na qual se entrelaçam momentos e experiências do grupo em relação ao percurso histórico que deu origem às escolas indígenas nas aldeias Pataxó, com suas propostas singulares no âmbito da chamada educação diferenciada; assim como da trajetória de deslocamentos territoriais motivadas muito frequentemente por conflitos e agressões; e por experiências e aspectos que dizem respeito à forma singular como D. Liça vivenciou diferentes etapas de sua vida até a vir se tornar "professora de cultura" em sua aldeia.

5 Para uma mais detalhada discussão da forma específica como os Pataxoop de Muã Mimatxi e os Xakriabá se apropriaram e imprimiram um caráter bastante peculiar à proposta pedagógica dos calendários socionaturais, ver Silva (2016). 


\section{OS TÊHÊY DE D. LIÇA}

D. Liça vem de Barra Velha, aldeia Pataxó no Sul da Bahia, onde viveu até a idade de 15 anos. Nos anos 1980 veio com sua família para Minas Gerais, e ficou por 22 anos na terra indígena Pataxó em Carmésia. Desde 2006 vive com sua comunidade na aldeia Muã Mimatxi em Itapecerica. D. Liça relata que não se escolarizou, não aprendeu aquele "ensino lá de fora"; o que aprendeu foi dentro do que ela refere, hoje, como o ensino tradicional de seu povo "o ensino da vida". E é essa referência que ela busca trabalhar com as crianças na escola de sua aldeia.

D. Liça iniciou a produzir seus Têhêy quando se mudaram para Muã Mimatxi, onde passou a atuar como professora em sua aldeia. Segundo ela, depois de diversos deslocamentos por outras terras do estado, foi neste lugar que se deram as condições para esse florescer de suas atividades, com os diferentes encontros que nele se tornaram possíveis com a natureza e seus ancestrais. D. Liça assumiu os dois temas que, na proposta curricular das escolas indígenas de Minas Gerais, foram negociados como sendo aqueles em que se aborda os conhecimentos tradicionais de cada povo. Em função disso, os "professores de cultura" (cf. PEREIRA, 2013) são indicados pelas comunidades como aqueles considerados aptos a essa função, sem ter que se submeter às exigências de titulação que os demais professores devem atender. No caso de Minas Gerais, a indicação para atuação como professor indígena em suas comunidades antecede a titulação (cf. LEITE, 2008) de forma que, se alguém é indicado e não tem a formação, essa será a motivação para que ele ou ela passe a frequentar os cursos em nível médio ou de graduação. Os professores de cultura, pela natureza do encargo a eles e elas atribuído e pelo reconhecimento como autoridade de conhecimento, não precisam passar por esse percurso "de fora", nas palavras de D. Liça.

O têhêy é de fato um instrumento de pescaria, usado mais especificamente por mulheres e crianças, no qual é possível capturar os peixes que servem para alimentar e devolver ao rio os que ainda são muito pequenos ${ }^{7}$. As pranchas desenhadas pro-

6 Muitas das informações contidas nesse tópico foram retiradas da entrevista narrativa com D. Liça, registrada em vídeo, por ocasião da produção do livro dos Têhêy. A entrevista foi realizada por Guilherme Marinho, então atuando como formador no SIE/UFMG.

${ }^{7}$ A palavra tem uma correspondente similar na língua maxakali. Têm sido registradas duas vertentes de reconstrução da língua ancestral entre os Pataxó: o Patxohã, que é referência para o sul da Bahia (cf. BOMFIM, 2012); e o Pataxoop, a partir das práticas em algumas aldeias de Minas Gerais. 
duzidas por D. Liça passaram a ser chamadas, por ela e o esposo, Kanatyo Pataxoop, como Têhêy de Pescaria de Conhecimento. A cada prancha é associado um tema por eles identificado como "valor", que pode ser "lido" na representação imagética do Têhêy. A leitura do Têhêy pode ser feita de diversas maneiras, e permite que todos os envolvidos, não importando a idade, possam fazer sua própria leitura. Segundo D. Liça, não serve somente a ensinar porque com ele "são todos ensinadores".

Como está registrado na monografia de Werymehe Braz (2019, p. 4):

O Têhêy é um livro onde se coloca a vida da aldeia. Com ele se pesca a alegria de ser e estar em Muã Mimatxi, de estar no mundo. Pescamos a nossa memória, a nossa cultura, os parentes gente, os parentes planta, os parentes bicho. E desde as origens somos acompanhados por Yãmixoop.

Kanatyo completa essa formulação quando explicita as dinâmicas coletivas que marcam a produção e circulação dos Têhêy, ou seja, eles vão "guardando toda essa experiência de vida e o importante é que o Têhêy, ele não morre, ele não finda, o Têhêy liga as várias histórias da vida, ele liga um conhecimento a outro conhecimento, liga um valor a outro valor, liga um tempo a outro tempo, liga uma geração a outra geração" (BRAZ, 2019, p. 9).

A práticas de uso dos Têhêy em Muã Mimatxi têm sido ampliadas e divulgadas, de forma que parte do acervo gerado se tornou objeto de produção editorial. O desafio nessa produção foi o de não trair o eixo imagético e oral dessas práticas, ou seja, tratava-se de evitar que a escrita alfabética viesse a ser usada como a tecnologia, ou a grafia, que enquadra e termina por dominar o modo como o material viria a ser utilizado após sua editoração. Chegou-se, assim, à proposta editorial que deu forma ao material ${ }^{8}$. Manteve-se, portanto, a dominância das imagens (como nos livros que tem somente ilustrações), e no verso de cada prancha foi gravado um QR-Code no qual D. Liça explora oralmente a leitura daquele Têhêy a partir do valor/tema que o identifica. A sequência de 69 pranchas termina com dez delas sem essa gravação, em um convite para o leitor, depois de ser guiado por tantas pescarias, se arriscar em sua própria leitura e navegação pelas imagens ${ }^{9}$.

8 Contamos com a consultoria de uma premiada ilustradora de livros infantis, Marilda Castanha, que havia realizado oficinas com os professores e ilustradores indígenas em outras ocasiões.

9 Foram inseridas duas das pranchas, como ilustração. O material está em fase final de publicação e está sendo estudada proposta de divulgação on-line para público externo em futuro próximo. 
Figura 1 - Têhêy - Ritual de Agradecimento

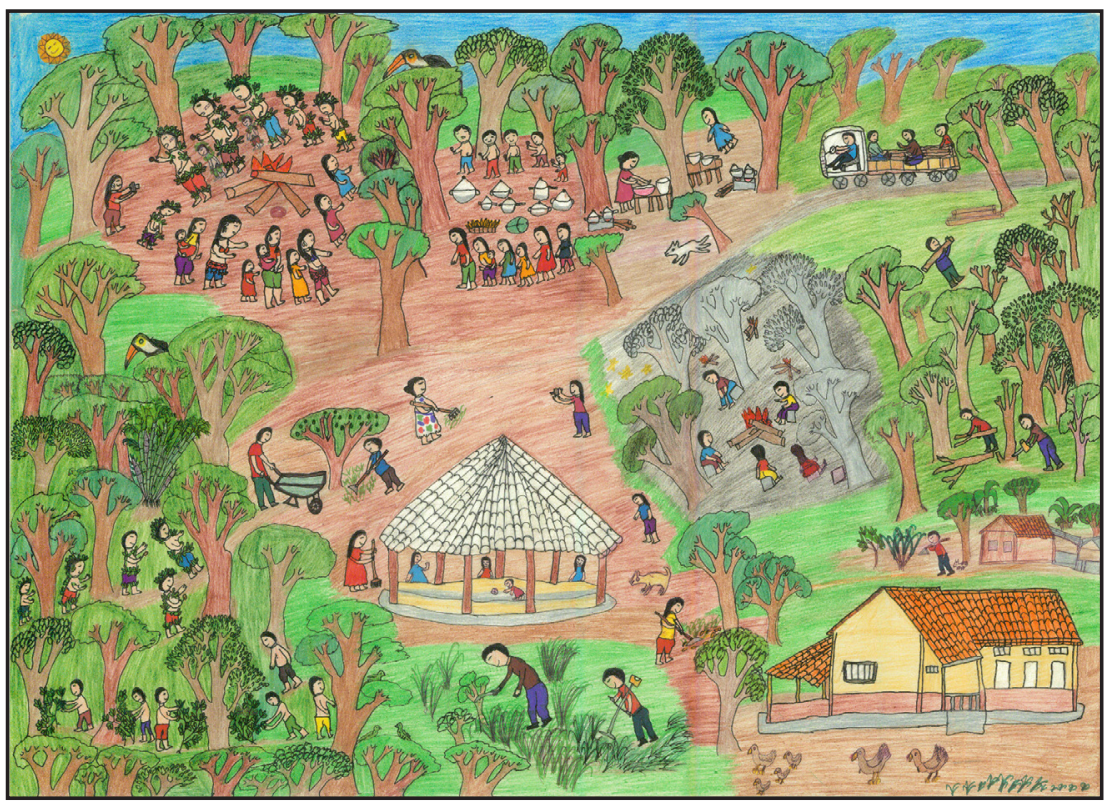

Fonte: Liça Pataxoop (2020).

Figura 2 - Têhêy - Apreciar com respeito

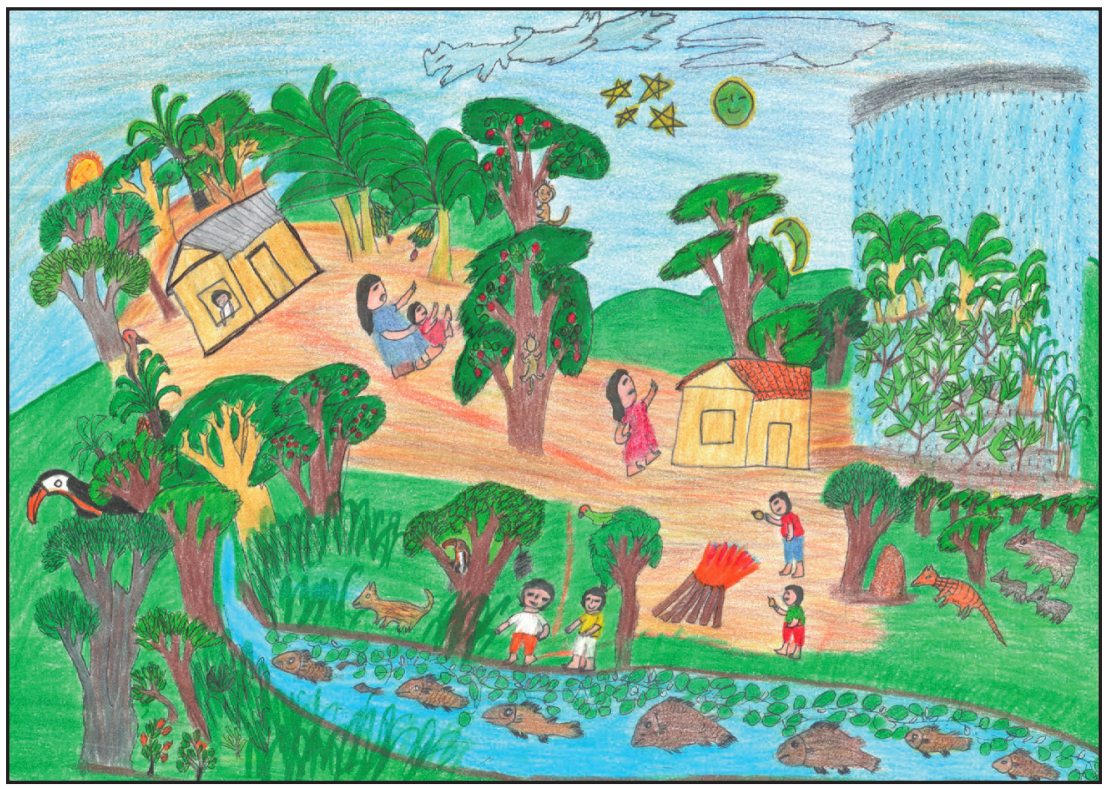

Fonte: Liça Pataxoop (2020). 
A proposta de se produzir livros de imagens em lugar de se propor materiais escritos em língua indígena foi levantada em mais de uma situação, e aparece em particular na provocação e reflexões que nos faz Ladeira (2014) quanto à desqualificação que marca as políticas educacionais voltadas para a alfabetização nas escolas indígenas, ao tratar implicitamente os índios como povos ágrafos, como cidadãos analfabetos. Ou seja, em outras palavras, assume-se implicitamente essa "inclusão" em uma ordem vigente na posição da falta e, de consequência, da subalternidade (cf. LADEIRA, 2014, p. 439). Sem que seja possível adentrar o debate muito interessante provocado por Ladeira, parece-nos significativo trazer aqui um caso explícito de recusa ativa da escrita alfabética. E quanto mais em se tratando de um grupo que tem o português como língua materna, em função do longo contato e das reiteradas violências nas relações com os atores e agências não-indígenas. Seria, no entanto mais acertado dizer que, através dos Tehey, D. Liça ativa sua própria escrita, cuja prática e centralidade nas dinâmicas da escola da aldeia, desde seu uso no livro de alfabetização, introduz "em pé de igualdade" um outro regime de escrita, capaz de interagir com a escrita alfabética sem ficar em desvantagem ou dela depender para sua efetiva realização. Ao contrário, como em diversas ocasiões D. Liça pode nos demonstrar, é possível solicitar a leitura dos Tehey a crianças muito pequenas e ainda não alfabetizadas; assim como é possível solicitar às maiores que escrevam em registro alfabético aquilo que têm a comentar, que "pescaram" no Tehey. Texto alfabético esse que será posteriormente controlado pelos demais professores da escola.

Como afirmam Braz e Melgaço (no prelo) a propósito dos Tehey: "Conhecimentos e sentimentos de pertencimento fazem parte de cada um dos Tehêys desenhados: conhecimento dos mitos que acompanham o povo Pataxoop, o uso dos saberes tradicionais e o conhecimento científico, a importância da terra e dos processos demarcatórios, a resistência contra a cultura hegemônica, enfim, é a vida expressa em desenhos-narrativas" (p.9).

\section{MEMÓRIA E RECONHECIMENTO ENTRE OS XAKRIABÁ}

Falar a respeito do passado colonial faz parte do nosso discurso político, do nosso humor, da nossa poesia, da nossa música, dos nossos relatos e de outras formas, em um sentido comum, de transmitir ao mesmo tempo a narrativa da história e uma atitude em relação a esta. (LINDA SMITH, 2018). 
A violência colonial nas Américas no séc. XVI foi responsável por um genocídio sem proporções anteriores: em torno de 60 milhões de indígenas foram reduzidos à menos de 6 milhões. Atualmente, no Brasil, a população indígena é estimada em menos de 1\% da população do país. Sua saga de sobrevivência passa por afirmar-se contra o caráter residual que a exploração capitalista Ihes confere. A existência de 300 etnias distintas e 250 línguas demonstra, de um lado, a riqueza e complexidade cultural que persiste e, de outro, as agruras para manterem-se num cenário em que as terras indígenas regularizadas são sistematicamente invadidas, incendiadas, pulverizadas por agrotóxicos, enfim, destruídas. Ou seja, o resultado do genocídio colonial prossegue com a dizimação no presente.

A reserva indígena, territorialidade empreendida pelo indigenismo brasileiro no contexto integracionista e protecionista, resulta numa limitação espacial com consequências étnicas. A definição do espaço de pertencimento e de circulação, nem sempre coerente com os espaços ancestrais e em geral restringindo o acesso a recursos importantes, como a água, expressa a noção de reserva indígena, ainda em voga quando se trata da demarcação de suas terras. Se o domínio de um território implica em sua utilização por seus próprios agentes, a ausência de recursos naturais para produção e reprodução da forma de vida específica de cada povo conforme sua tradição tem reduzido as perspectivas de futuro, sobretudo para os mais jovens.

No Brasil, o paradigma integracionista, que previa a incorporação dos "silvícolas" à comunidade nacional por meio da renúncia à sua identidade e submissão à referência da modernidade ocidental vigorou no aparato jurídico até a Constituição Federal de 1988. A assimilação exprime a escala de um epistemicídio (SANTOS, 2014) que se traduziu num vasto apagamento de saberes, junto com a destituição forçada de laços com o território, extinção de línguas e tecnologias produtivas, dissolução de relações com o sagrado e com os ancestrais, e aniquilamento de formas de arte e de cuidado. A saga desses povos para sobreviverem até nossos dias ocorre em contextos de violência e silenciamento, faces do genocídio perpétuo.

As lutas dos povos indígenas por reconhecimento de seu direito à manutenção de formas especificas de viver e de pensar, de manter e utilizar suas línguas e culturas, seus modos próprios de produção, com base nos princípios de autonomia e autodeterminação assume, a partir dos anos de 1990, relações com o aparato escolar. É nessa dinâmica que se insere a ação Saberes Indígenas na 
Escola (SIE). A produção de material específico para processos escolares tem nos revelado aspectos da aproximação e apropriação do aparato escolar. Interessa-nos aqui particularmente, a importância conferida à disseminação das "memórias de violência", estratégia adotada pelos Xakriabá.

\section{OS XAKRIABÁ E A ESCOLA: UMA CENA ORIGINAL}

A Terra Indígena Xakriabá teve seu processo de identificação iniciado em 1969 alcançando, em 1979 a demarcação; somente em 1987 ocorreu a homologação da terra indígena. A história desse grupo é marcada por violências e por forte e sistemática desqualificação da identidade indígena. Nomeados por órgãos do governo estadual como índios gamela, a invisibilização foi intensificada com o abandono forçado da língua - originalmente pertencem ao tronco macro-jê, língua Akwén e da prática de rituais, assim como com processos de individualização do acesso a terra, os quais foram impostos por órgãos governamentais e por fazendeiros que invadiram o território. Na década de 1980 os conflitos se intensificaram e, em 1987 ocorreu a Chacina do Sapé, na qual três importantes lideranças foram assassinadas, casas destruídas e mulheres e crianças vitimadas. É o momento denominado pelos Xakriabá de revolução ${ }^{10}$. Após a chacina ocorreu a homologação da Terra Indígena Xakirabá sob pressão indígena e apoio de instituições indigenistas.

Atualmente a Terra Indígena Xakriabá possui 46.415, 9242 hectares localizados nos municípios de São João das Missões e Itacarambi e a Terra Indígena Xakriabá Rancharia possui 6.798,3817 hectares nos mesmos municípios, tratando-se de dois processos de demarcação com registros distintos. No censo demográfico de 2010 foram contabilizados 10.221 Xakriabá e estima-se atualmente uma população de mais de 11 mil distribuídos nas 33 aldeias.

As resistências e negociações ao longo de sua história levaram os Xakriabá a um intenso contato intercultural. A nomeação "índios misturados" é uma fórmula que por vezes utilizam para significar as relações interétnicas e inter-raciais, com quilombolas que viviam processos semelhantes de perseguição na região; com grupos de outros estados, sobretudo Bahia, que se deslocavam expulsos de

\footnotetext{
10 SANTOS (1997) realizou uma detalhada análise da documentação histórica da região e da presença indígena, cotejada com substanciais narrativas dos Xakriabá sobre a luta pelo território e pela legitimidade étnica.
} 
sua terra; com brancos com os quais trabalhavam na agricultura assalariada nas fazendas de café e cana da região e em outros estados ${ }^{11}$. A miscigenação, o abandono forçado da língua, de rituais e práticas culturais (como a cerâmica artesanal) marcam a identidade étnica Xakriabá. Há um forte investimento na retomada de práticas culturais tanto pelos mais velhos, quanto pela juventude. Recentemente, têm realizado intercâmbios com o povo Xerente, do mesmo tronco linguístico, na tentativa de revitalização da língua materna.

Em 1995 iniciou-se o Programa de Implantação das Escolas Indígenas de Minas Gerais (PIEI), com a formação de professores indígenas em nível médio para atuarem nas escolas. Desde esse período, a presença da escola em terra indígena, intensificada a partir dos anos 2000, e a presença constante dos indígenas em instituições de ensino superior estão articuladas à afirmação da identidade étnica Xakriabá na região. Uma ocorrência na audiência com a prefeitura de São João das Missões em 1997 incorporou-se à memória Xakriabá e é sistematicamente narrada. Nas palavras do Cacique Domingos:

Foi em 1998 que nós fomos lá na prefeitura pra dizer pro prefeito que a gente queria escola nossa, com professores nossos. E ele falou que podia vir secretaria, podia vir faculdade, podia vir quem fosse para formar gente aqui, que ele duvidava que os índios Xakriabá aprendessem e que soubessem alguma coisa para ensinar as crianças. Que se os índios mesmo fossem ensinar os índios, nós íamos ficar sem saber nada. Nós então resolvemos que se não fosse com nossos professores, nós não queríamos escola aqui dentro. Foi quando passamos para escola do estado. No começo tinha até gente daqui de dentro que duvidava dos nossos professores e queria levar os filhos pra estudar fora. Mas nós insistimos. E hoje nossas escolas são melhores que as de fora, porque nossos professores seguem a nossa tradição. Aprendem lá fora, mas sem deixar nossa cultura. E agora, tem gente de fora que quer colocar criança aqui. (Cacique Domingos Xakriabá). ${ }^{12}$

\footnotetext{
11 Índios misturados foi uma formulação também discutida por Santos (2010). Anastácio (2018) registra que o tema da "mistura" e da legitimidade étnica e territorial Xakriabá estiveram presentes de forma intensa nas narrativas dos contadores de histórias que acompanhou em sua pesquisa. Embora considere-se que a denominação "misturados" promova o estereótipo da perda ou enfraquecimento cultural, Andrade (2019, p. 274) aborda a "mistura" a partir de outra significação: o apreço Xakriabá pela variedade, pela diferença que não hierarquiza e pela multiplicidade que "vem dos antigos, assim como as variedades antigas do milho".

12 Esse registro foi colhido no Seminário do Sub-Projeto Gestão da Educação Escolar Indígena e Quilombola, do Observatório da Educação Escolar Indígena da UFMG, em 2014.
} 
Essa ocorrência produz lastro memorial nos eventos que discutem educação na TI Xakriabá e fora dela, e também ocorre nos trabalhos monográficos desenvolvidas por estudantes indígenas. A reiteração dessa narrativa assume a função de afirmar a capacidade de luta e sabedoria dos Xakriabá e, ao mesmo tempo, apresenta a educação escolar como aparato indígena recriado com função emancipadora, ou indigenizada (cf. SAHLINS, 1997).

\section{MEMÓRIAS DE VIOLÊNCIA, NARRATIVAS DE RESISTÊNCIA}

Em 2018 realizamos, no âmbito da ação Saberes Indígenas na Escola - TI Xakriabá, o Seminário "O tempo passa, a história fica". O título era uma referência à publicação de 1997, que seria retomada em segunda edição, revista e ampliada. A realização dos seminários consiste numa prática peculiar dos Xakriabá quando se trata da produção, na fronteira do território, de conhecimentos que emergem em parceria. Sem a intenção de detalhamento, cabe-nos destacar que os seminários e assembleias consistem em momentos de autorização e validação daquilo que se produz sobre e com os Xakriabá. Nesse seminário em específico, a equipe do SIE levou algumas indicações de revisão da primeira edição do livro publicado em 1997, que era composto por narrativas sobre a chacina, em prosa e em verso, vinte e um contos e um glossário com trinta palavras em língua Xakriabá. As indicações de revisão foram consolidadas depois de discussões em cada uma das dez aldeias que participam da ação SIE. Após um dia de intensos debates, atravessados pelo cuidado com a autoria de experiências e discursos, concluiu-se que o livro era a expressão do que foram e não seria alterado ou retificado, num declarado esforço para preservar o tempo e o contexto em que as deliberações que compuseram o primeiro volume foram produzidas. Era preciso ampliar a história em um outro volume, porque o tempo passa... e também, republicar o primeiro volume, porque a história fica. Atualizar sem perder a originalidade.

Nas palavras da liderança da aldeia Prata, Valdemar Ferreira dos Santos, "A luta rendeu... muito jovem achou a carruagem andando". Com essa metáfora, a liderança mobilizou a memória de desafios enfrentados pelos primeiros professores, muitos dos quais presentes no seminário. As narrativas se seguiram evidenciando condições singulares do processo de escolha dos jovens que saíram das aldeias pela primeira vez para estudar, as distâncias e receios vencidos e o contato inédito com 
outras etnias indígenas. A combinação entre a evocação de um passado constitutivo e os usos sempre seletivos da memória, nos permite argumentar que a memória é um componente estruturante da interculturalidade a proporcionar contraposição à narrativa hegemônica. Na medida em que se valoriza a história narrada, mecanismo que Pilar Cuevas (2013) cataloga como a "recuperação coletiva da história", a memória pode ingressar num exercício cruzado de sentido acadêmico e político de modo a ampliar o arcabouço epistemológico ao nível do reconhecimento dos saberes ${ }^{13}$.

Como assevera Martins (2015, p. 297), "as vozes subalternizadas pelo imperialismo da razão metonímica, moderna, ocidental, falam na medida em que possam determinar os seus destinos e, simultaneamente, possam desafiar as premissas das lógicas opressoras". Afinal, o conhecimento crítico exige a crítica ao conhecimento. E essa crítica precisará sempre emergir das práticas de luta por emancipação e não da internalidade do conhecimento científico. Nessa perspectiva, tomamos por base algumas premissas da crítica dos povos indígenas à história segundo a análise de Smith (2018), quais sejam, as ideias de história universal, ordem cronológica e narrativas coerentes.

Como concluímos em nossas análises pregressas (MIRANDA, 2016, p. 274), a legitimidade do conhecimento produzido por indígenas é definida por sua função em contextos específicos e não deriva de uma ordem universalmente válida e nem de uma cronologia sequencial. No contexto atual Xakriabá, a história de ocupação do território demarcado ganha primazia, num tempo em que a expansão da demarcação é uma necessidade para a sobrevivência e encontra-se ameaçada pelas forças políticas reacionárias. Assim, retomada é o significante que permite recuar no passado e avançar no futuro, simultaneamente retomando as violências anteriores à chacina de 1987 e as lutas de retomada das fronteiras territoriais na segunda década dos anos 2000, tendo por referência o documento de doação de terras de 1728, e por eles novamente registrado em 1856.

A validação desse conhecimento histórico é conferida pelas práticas de saber que acessam as "pessoas mais velhas", "verdadeiras bibliotecas vivas" como se

\footnotetext{
${ }^{13}$ Estamos em acordo com as formulações de Santos (2014, p. 225) acerca da caracterização dos saberes que foram subjugados pelos dispositivos de poder da modernidade ocidental e concordamos que a emergência desses saberes "confronta a lógica da monocultura do saber científico e do rigor identificando outros conhecimentos e outros critérios de rigor e validade que operam de forma credível nas práticas sociais".
} 
ouve repetidamente entre os Xakriabá. Trata-se de elaborar táticas de validação coletiva, como os seminários e assembleias, e enfrentar o desafio de expandir as vozes que reverberam as memórias. A lista de pessoas a entrevistar configurou um quadro de vinte e oito pessoas, número superior ao primeiro volume e inferior à premissa inicial de que todas as lideranças deveriam falar. Foi a pesquisadora indígena Maria José Alkimim quem resolveu o dilema: "no livro não cabem todos. E isso é muito bom porque mostra que somos muitos. E que temos que fazer novos livros para contar nossa história".

Enredos plurais sobre a violência e perspectivas que convocam vários horizontes de temporalidade (CARDINA; MARTINS, 2018) compõem a dinâmica narrativa e destituem a premissa de verdade histórica. Admitem-se, ou melhor, buscam-se múltiplas perspectivas, o que procede a atualização de uma característica original dos Xakriabá, qual seja, o apreço pela variedade, pela diferença que não hierarquiza e pelas trocas que conturbam os limites. Afinal, as análises sobre "índios misturados" nos ajudam a entender que a mobilização da memória segue rastros sobre as diferenças e multiplicidades de ser Xakriabá, e não sobre ser mais ou menos Xakriabá.

Por esse caminho metodológico emergiram narrativas a partir de diferentes aldeias, formuladas por homens e mulheres e narradas de muitos modos, que puderam elucidar várias camadas de violência e resistência. Destacamos aqui a narrativa da liderança Zé de Benvino, da aldeia Sapé, em primeira pessoa, e de Vilma Nunes dos Santos, também da aldeia Sapé, esposa de Zé de Benvindo, em terceira pessoa:

O nosso povo colocava as roças, os fazendeiros colocavam o gado para comer. E não tinha a quem recorrer pois a polícia era do lado dos fazendeiros, pois era tempo de ditadura Militar. [...] Muitos outros casos de violência aconteceram. Colocaram veneno num tanque em que todos pegavam água, o gado que bebeu da agua caiu o pêlo todo, as pessoas que usavam da água sentiram o cheiro e não usaram a água. Deram um arroz envenenado para uma família. Antes de cozinhar o arroz, o homem que recebeu o arroz colocou um pouquinho na boca e morreu. Se não fosse isso teria morrido a família toda. Devido a ataques desse tipo, muitas das nossas famílias saíram para fora e estão fora até hoje.

$[\ldots]$ 
Os invasores aqui da nossa região começaram a cercar tudo, Vargem, Lagoinha, até o Peruaçu. Foram nos deixando num círculo e o único jeito foi ir para a luta. Foi então que alguns homens foram até Brasília. Eles tiveram muita dificuldade até para entrar na FUNAl, só conseguiram porque arrumaram um advogado.

Eles foram barrados pelo Major, que questionava se eles não eram índios, não queria deixá-los sentar em cadeira e alegava que não tinham as características indígenas. Foi então que eles responderam que não tinha culpa se não tinha as características, mas que eram descendentes e que tinham direitos. Foi nessa época que tiveram que escolher o cacique e indicaram $Z$, mas ele não aceitou porque não sabia ler. $R$ também não sabia ler, mas tinha um filho que estudava e já sabia ler e escrever e então ele aceitou ser o cacique e falou que ia estudar e um dia ele mesmo ainda ia escrever e ler as cartas. E começou a estudar com o material do seu filho e logo desenvolveu e já conseguia escrever e ler as cartas.

Em entrevista com dona Vilma Nunes dos Santos, ela falou da sua luta e de muitas mulheres daquela época, que foram tempos difíceis. Quando eles moravam na aldeia Sapé ficavam mais era no mato, não podiam ficar em casa porque eram perseguidos e ameaçados pelos fazendeiros. Tinha um local muito importante onde os indígenas se sentiam mais seguros e protegidos, que era um local chamado pau loro, lá era onde eles construíam barracos de lonas para se abrigar da chuva, quando eram expulsos de suas casas. Dona Vilma narra a preocupação do seu esposo, conhecido como Zé de Benvino. Quando ele precisava sair para trabalhar ou para viajar para Brasília em busca dos nossos direitos, toda a família era ameaçada, os fazendeiros mandavam recados com ameaças, teve um dia que seu Zé de Benvino foi para um mutirão na roça do senhor $\mathrm{M}$ e os fazendeiros foram na casa dele. Ele tinha matado um porco para a alimentação da família, quando os fazendeiros chegaram invadiram a casa derrubaram tudo, pegaram a comida que estava preparada jogaram tudo no meio do terreiro. Nesse dia eles ficaram sem almoçar. Ela conta que naquela época chovia bastante e naquele dia era um dia de muita chuva e tudo o que eles tinham foi jogado na chuva, roupas, colchão, alimentos, ainda mataram uma vaca e galinhas e fizeram uma festa. Após esse ato de violência a família de dona Vilma foi se abrigar na casa de seu Manuelim no Itapicuru. (OLIVEIRA; ALKIMIM; MIRANDA, 2020, p. 22).

Convocar histórias que se cruzam nas memórias que sobrevivem às várias camadas da violência colonial tem sido uma tática para desfazer o trauma. Afinal, 
como sempre nos lembra Sr. Valdemar, a herança indígena para os jovens é a luta. Essa é a função da republicação de "O tempo passa... a história fica". Do nosso ponto de interesse, trazer aqui um breve registro dessa memória é um modo de ultrapassar as fronteiras que segregam o que não pode ser assimilado. É nossa tentativa de expandir o lastro que nos ajuda a compreender como, apesar de toda a força e das múltiplas táticas de aniquilamento, esses povos resistem.

\section{ESCRITA E TERRITÓRIO ${ }^{14}$}

O capitalismo com toda sua matriz colonizadora, só vai reconhecer os nossos territórios como importantes lugares para elaborar e guardar conhecimentos, no dia em que não existir mais nenhuma árvore, porque no dia em que já não existir mais nenhuma árvore, nós povos indígenas ficaremos a refletir onde irão escrever com essa caneta? (Célia Xakriabá).

O movimentar do inscrito e escrito no território Xakriabá se desdobra de acordo a luta pelo território. O que a terra fala e ensina, depois de muitas assuntadas, a gente aprende a transcrever. Tal movimento não pode ser tratado apenas como mais uma escrita, pois é resultado do que, inspirado na luta pela chegada da escola no território Xakriabá, chamamos do amansamento da escola, do giz e da caneta. Lutas e a própria escrita corporificadas pelas narrativas nativas e narrativas ativas na produção coletiva, enunciadas na produção de cunho participativo com a presença de professores indígenas na interlocução com os narradores que são os mais velhos da comunidade. São eles os nossos primeiros professores, no mesmo sentido que nós povos indígenas aprendemos com a professora mais velha e sábia que é a mãe ou avó terra/território, a terra como avó porque é mãe duas vezes, porque ela também é mãe de nossas mães.

A liberdade de expressão em nossas próprias narrativas seja na língua indígena ou nas mais variáveis maneiras de falar, é também fundamental para nós. Reafirmamos que nossas línguas seguem vivas, uma vez que segue vivo o nosso modo de falar. O nosso modo de falar e narrar resistiram às violências coloniais que nos obrigaram ao uso da língua estrangeira, e ao apagamento de nossas formas

\footnotetext{
${ }^{14}$ Neste tópico decidimos manter a redação original de Célia Xakriabá e, nesse sentido, manter os registros pronominais que ela usou, de forma a garantir a multiplicidade de vozes que compuseram este texto.
} 
próprias de expressar nossas vivências. Nós temos uma contribuição significativa na transmissão dos nossos conhecimentos ancestrais por meio da transmissão das nossas narrativas.

Lutamos e construímos uma educação do jeito que a gente quer, sem matar o que a gente é, uma educação que respeite o nosso modo de vida. Não dá para seguir reproduzindo um plano nacional de educação, matrizes curriculares, que também foram responsáveis pela colonização do pensamento e dos corpos. Educação que desconsiderou e reproduziu por muitos séculos uma história de violência, contra os povos indígenas e negros no Brasil. É urgente que a educação amplie sua compreensão de que a produção da ciência não se faz apenas na elaboração do pensamento, mas também nas relações sociais, por meio das mais variadas narrativas e narradores. Precisamos de uma educação que traga a experiência das práticas culturais para a centralidade, reconhecendo a sua diversidade como parte e totalidade do ensinar que resgate a nossa autonomia, valorize e se reconecte com a ancestralidade. Precisamos também questionar a atual base nacional comum, as matrizes curriculares que chegam em nossas escolas, precisamos propor um projeto amplificado que considere e respeite outras agências e agentes como autores altivos do conhecimento.

Não se trata de ausência de mecanismo jurídico, que garanta o direito das nossas escolas nas comunidades indígenas produzirem os próprios materiais e elaborarem as próprias matrizes curriculares; trata-se de uma decisão política de assegurar a implementação nos próprios estados. Por isso temos dito que toda política pública que atende os povos indígenas, como o caso da educação escolar indígena diferenciada, para serem realmente asseguradas precisam ser tratadas, compreendidas não apenas como projeto de governo e sim projeto de Estado, do contrário estaremos reféns da boa vontade dos governantes. Nós povos indígenas acreditamos em uma educação que dialoga com o movimento da vida, com o viver no território, porque o território também nos ensina. Atribuo o aprender por meio dos conhecimentos tradicionais como um "aprender sem se prender", sem prender os corpos em único lugar de uma sala, o lugar do imaginário onde se aprende, porque quando cercamos os corpos limitamos a mente. Nós povos indígenas tempos muito a contribuir a partir de nossa experiência de educação indígena que tem um conhecimento muito potente e que se as instituições bem 
soubessem, escutariam mais o que temos a contribuir, porque nós povos indígenas temos condições de colaborar com um outro projeto político educacional e de bem viver para o país. Junto com toda crise política, existe também uma crise educacional e intelectual; e os intelectuais nativos certamente poderão contribuir trazendo a epistemologia nativa como uma possibilidade de cura. Esse pensamento da educação indígena se orienta e se relaciona com a organização social comunitária e com o território, que é onde está a sustentação da vida de um povo. Isso tem origem na sabedoria ancestral dos nossos povos indígenas.

Foi com esse propósito de também amansar, descolonizar a escrita e trazer outras narrativas, escritas pelos próprios povos indígenas, que a ação Saberes Indígenas na Escola se apresenta como uma importante ocasião que proporcionou a produção de materiais desenvolvidos pelos próprios professores indígenas e interlocutores das comunidades, fortalecendo a experiência de produção coletiva feita a muitas mãos. Trata-se não apenas de um escrever, é um tecer, tessitura essa que demanda uma outra temporalidade, resultando numa importante incidência na política educacional em Minas Gerais.

Essa soma de experiências culminou no fortalecimento da proposta de reconstrução das matrizes curriculares em diversos povos de Minas Gerais, iniciando com os Maxakali, onde se deu a primeira reelaboração, e depois se multiplicando em outros territórios com os Xakriabá, Pataxó, Krenak, Xukuru Kariri e Kaxixó. Essa reconstrução das matrizes curriculares que traz o ensinar na escola sustentado no modo ser de cada povo, compreendido nas mais variadas maneiras de ensinar geografias, matemáticas, histórias, ciências dentre outras, foi resultado de um intenso processo de luta, depois de uma ampla discussão e consulta em cada povo. No final de 2018, foram aprovadas pela Secretaria de Estado de Educação de Minas Gerais as matrizes curriculares produzidas por cada povo, respeitando cada realidade. Foi uma conquista importante para os povos indígenas de Minas Gerais pois, assim como com os demais povos indígenas do Brasil, os órgãos de Estado sempre tiveram muita resistência de aceitar e compreender uma outra possibilidade de ensinar, que não seja aquela imposta e controlada por um único sistema.

Neste sentindo a educação indígena se apresenta para uma criança, jovem indígena como uma educação que ensina para várias possibilidades e escolhas. 
Seja para permanecer no território, seja para transitar em outros conhecimentos fora do território, como na universidade. Ensinamos o novo sem perder a conexão com o velho, que é onde nos conectamos com a ciência do território. Conhecer e ressignificar esse novo para nós, povos indígenas, só tem sentido porque amansamos, e não apenas nos reapropriamos da escrita como uma ferramenta de luta, já que a caneta se apresenta como a arma do século XXI. Mas se a caneta é a arma do século XXI, nós acreditamos que nossas identidades, nossas narrativas, nossos diferentes modos de fazer também o são.

\section{CONSIDERAÇÕES FINAIS}

Retornando ao que foi afirmado no início do artigo, mais do que abordar cada produção editorial como parte de um programa maior que determina essa ou aquela direção, parece-nos interessante que cada situação seja assumida em sua particular contingência, na história das relações entre um determinado povo indígena ou mais precisamente, uma comunidade, e o que efetivamente vem a ser interessante negociar e coproduzir. Contando, de um lado, com o repertório ativo e atuante da própria comunidade, seja pelas possibilidades das artes verbais e visuais que lhe são próprias, seja em termos das barganhas políticas que sempre acompanham esse tipo de produção; e, de outro, contando com as capacidades e competências, mas também com as limitações e equívocos de seus parceiros não-indígenas. A produção dos Tehey de D. Liça não resulta da "encomenda" de nenhum programa governamental; e nem tem se assujeitado às exigências das diferentes agências governamentais (e não) que atravessam incessantemente as práticas cotidianas das escolas indígenas em Minas Gerais. Esse exemplo serve a nos chamar a atenção para, como sugere Stengers (2018), ao embarcar em cada uma dessas produções, praticar o slow down, e pensar que algo mais importante está em jogo, algo que deve ser ouvido e percebido sempre na presença de nossos interlocutores, por entre as constrições e constrangimentos, e também potencialidades não imediatamente percebidas, que cada situação pode oferecer. Como se dizia antes, ao ter em mãos um desses "produtos editoriais", muito desse percurso se perde, a história se apaga. E assumimos que estamos diante de um "livro didático". Que fique bem claro, no que diz respeito aos casos aqui apresentados, que se trata exatamente de desconstruir essa ideia de execução e 
implementação linear de "materiais didáticos". A discussão com colegas de outros países, a partir de outras políticas implementadas, como as políticas muito centralizadas que caracterizam a experiência mexicana; e, ao mesmo tempo, com uma história de línguas escritas que supera em muito o enquadramento promovido pela colonização (cf. Briseno, Rockwell, neste número) pode nos abrir outros e muito diversificados horizontes. Sem que exista o imperativo de uma direção unificada e unificante das posições e atividades e parcerias a serem propostas.

As decisões quanto às atividades da ação Saberes Indígenas na Escola, nesse período ativada como parte de um programa governamental entre os povos indígenas de MG, foram em parte orientadas pela intenção de assumir mais de perto a dimensão da pesquisa, ou assumir as muitas pesquisas que circulam entre as comunidades como definidoras do perfil do programa. Isso significou inclusive reduzir o número de participantes, dando menos ênfase à ideia de formação continuada de professores, no sentido de uma replicação de atividades já previamente definidas e aplicadas indistintamente a todos eles, e se orientando mais pela identificação dos projetos de pesquisa "em curso" que deveriam ser sustentados e promovidos. Essa orientação - que assumiu horizontes de trabalho e proposições específicas para cada um dos povos envolvidos ${ }^{15}$ - pode ser entendida aqui como uma forma de exceder (cf. DE LA CADENA, 2010) aquilo que está previsto nas políticas governamentais e levar adiante cosmopolíticas próprias dos povos indígenas.

Por outro lado, voltando-se em modo mais específico para o tema das relações com a escrita, cabe mais uma vez nos remeter às reflexões de Ivan Illich (1993; 1995) sobre a história da leitura, em que o autor busca recuperar o livro, ou a "página escrita" do processo de redução e estreitamento de suas possibilidades de interação e de experiência com pessoas e grupos sociais, em função da sua excessiva e quase exclusiva associação e demarcação a partir das práticas escolares, e das formas de relação com a escrita marcadas pela intensidade do processo de escolarização do social, na acepção que os historiadores da educação dão a essa expressão (cf. FARIA FILHO, 2003). O amansamento da escrita - junto

\footnotetext{
${ }^{15}$ As atividades realizadas entre 2013 e 2019 deram origem à série de publicações de cada um dos povos envolvidos, série identificada nas primeiras páginas dos livros com uma logomarca de identidade gráfica e um diferente texto programático construído por cada um deles.
} 
com a escola, como reitera Célia Xakriabá (CORREA; XAKRIABÁ, 2018) - e sua inserção na história própria de cada povo em sua singularidade é o que interessa aferir para, a partir desses enquadramentos, prosseguir.

\section{REFERÊNCIAS}

ANASTÁCIO, Vanessa Lorena. Um povo da palavra: ressonâncias da cultura acústica na educação escolar indígena Xakriabá. 2018. Dissertação (Mestrado em Educação e Formação Humana) - Universidade do Estado de Minas Gerais, Belo Horizonte, MG, 2018.

ANDRADE, Rebeca C. Resistências semiáridas: sobre a produção e circulação de conhecimentos pela rede sociotécnica do milho, estiagem e os indígenas Xakriabá do norte de Minas Gerais. 2019. Tese (Doutorado em Educação: Conhecimento e Inclusão Social) - Universidae Federal de Minas Gerais, Belo Horizonte, MG, 2019.

BLASER, Mario; DE LA CADENA, Marisol. Introduction: Pluriverse. Proposals for a world of many worlds. In: DE LA CADENA, M.; BLASER, M. (Ed.). A world of many worlds. Durham: Duke Univ. Press, 2018.

BOMFIM, Anari Braz. Patxohã, "Língua de Guerreiro": um estudo sobre o processo de retomada da língua Pataxó. 2012.Dissertação (Mestrado em Estudos Étnicos e Africanos) - Universidade Federal da Bahia, Salvador, BA, 2012.

BRAZ, Saniwê Alves. Alfabetizar cantando na aldeia Muã Mimatxi. 2016. 46 f. Trabalho de Conclusão de Curso (Curso de Formação Intercultural para Educadores Indígenas) Universidade Federal de Minas Gerais (UFMG), Belo Horizonte, MG, 2016.

BRAZ, Werymehe A. Tehêys de Pescaria de conhecimento. 2019. Trabalho de Conclusão de Curso (Curso de Formação Intercultural para Educadores Indígenas) - Universidade Federal de Minas Gerais (UFMG), Belo Horizonte, MG, 2019.

BRAZ, Werymehe A.; VALADARES, Juarez M. A educação na aldeia e na escola indígena de Muã Mimatxi: o tehêy de pescaria de conhecimento. Educação e Pesquisa, São Paulo, v. 47. [no prelo].

CARDINA, Miguel; MARTINS, Bruno Sena (Org.). As voltas do passado: a guerra colonial e as lutas de libertação. Lisboa: Tinta da China, 2018.

CARVALHO, Maria Rosário. Os Pataxó de Barra Velha: seu subsistema econômico. 1977. Dissertação (Mestrado em Ciências Humanas) - Programa de Pós-Graduação em Ciências Humanas da Universidade Federal da Bahia, Salvador, BA, 1977. 
CORREA, Célia Nunes; XAKRIABÁ, Célia. O barro, o genipapo e o giz no fazer epistemológico de autoria Xakriabá: reativação da memória por uma educação territorializada. 2018. Dissertação (Mestrado em Desenvolvimento Sustentável) - Universidade de Brasília, Brasília-DF, 2018.

CUEVAS, P. Memoria colectiva: hacia um proyecto decolonial. In: WALSH, K. (Org.). Pedagogias decoloniales. Practicas insurgentes de resistir, (re)existir y (re)vivir. Tomo 1. Quito: Ediciones Abya-Yala, 2013.

DE LA CADENA, Marisol. Earth beings. Ecologies of practice across Andean worlds. Durham: Duke Univ. Press, 2015.

DE LA CADENA, Marisol. Indigenous cosmopolitics in the Andes: conceptual reflections beyond "politics". Cultural Anthropology, [s.I.], v. 25, n. 2, p. 334-70, 2010.

ESCOBAR, Suzana A.; GALVÃO, Ana Maria O.; GOMES, Ana Maria R. Culturas do escrito nas associações e projetos sociais indígenas: um estudo sobre os Xakriabá, Minas Gerais. Revista Brasileira de Educação, Rio de Janeiro, v. 22, n. 68, p. 231-53, 2017.

FARIA FILHO, Luciano Mendes. O processo de escolarização em Minas Gerais: questões teórico-metodológicas e perspectivas de pesquisa. In: VEIGA, Cynthia Greive; FONSECA, Thais Nívea de Lima (Org.). História e historiografia da educação no Brasil. Belo Horizonte: Autêntica, 2003. p. 77-97.

ILLICH, Ivan. Um apelo à pesquisa em cultura escrita leiga. In: OLSON, D. R.; TORRANCE N. (Ed.). Cultura Escrita e Oralidade. São Paulo: Ática, 1995. p. 35-54.

ILLICH, Ivan. In the Vineyard of the Text: a commentary to hugh's didascalicon. Chicago: University of Chicago Press, 1993.

LADEIRA, Maria Elisa. "De "povos ágrafos" a "cidadãos analfabetos": as concepções teóricas subjacentes às propostas educacionais para os povos indígenas no Brasil". In: CARNEIRO DA CUNHA, Manuela; CESARINO, Pedro (Org.). Políticas culturais e povos indígenas. São Paulo: Editora Unesp; Cultura Acadêmica, 2014. p. 435-54.

LEITE, Lucia Helena Alvarez. Os professores indígenas chegam à universidade: desafios para a construção de uma educação intercultural. In: DINIZ-PEREIRA, J. E.; LEAO, G. M. P. (Org.). Quando a diversidade interroga a formação docente. Belo Horizonte: Autêntica, 2008. p. 37-55.

LIMA, Amanda M. A. O livro indígena e suas múltiplas grafias. 2012. Dissertação (Mestrado em Estudos Literários) - Universidade Federal de Minas Gerais, Belo Horizonte, MG, 2012. 
MARTINS, Bruno Sena. Violência colonial e testemunho: para uma memória pósabissal. Revista Crítica de Ciências Sociais, Coimbra, n. 106, p. 105-26, 2015.

MIRANDA, Shirley Aparecida. Dilemas do reconhecimento: a escola quilombola "que vi de perto". Revista da Associação Brasileira de Pesquisadores(as) Negros(as), Goiânia, v. 8, n. 18, p. 68-89, 2016.

OLIVEIRA, Joel Gonçalves; ALKIMIM, Maria José Nogueira; MIRANDA, Shirley Aparecida. O tempo passa e a história fica. Belo Horizonte: Fino Traço, 2020. V. 2.

PATAXÓ, Kanatyo; PATAXÓ, Siwê. Pega fruta. Belo Horizonte: Fino Traço, 2017.

PATAXOOP, Liça. Tehey: Pescaria de Conhecimento. Belo Horizonte: Fino Traço, 2020.

PEREIRA, Verônica M. A circulação da cultura na escola indígena Xakriabá. 2013. Tese (Doutorado em Educação: Conhecimento e Inclusão Social) - Universidade Federal de Minas Gerais, Belo Horizonte, MG, 2013.

RIVERA CUSICANQUI, Silvia. Sociología de la imagen: miradas ch'ixi desde la historia andina. Buenos Aires: Tinta Limón, 2015.

RIVERA CUSICANQUI, Silvia. Ch'ixinakax utxiwa: una reflexión sobre prácticas y discursos descolonizadores. Buenos Aires: Tinta Limón, 2010.

SAHLINS, Marshall. O "pessimismo sentimental" e a experiência etnográfica: por que a cultura não é um "objeto" em via de extinção (parte II). Mana, Rio de Janeiro, v. 3, n. 2, p. 103-50, 1997.

SANTOS, Ana Flávia Moreira. Do terreno dos caboclos do Sr. São João à Terra Indígena Xakriabá: as circunstâncias da formação de um povo - um estudo sobre a construção social de fronteiras. 1997. Dissertação (Mestrado em Antropologia) - Universidade de Brasília, Brasília-DF, 1997.

SANTOS, Boaventura de Sousa; MENESES, Maria Paula. Epistemologias do sul. São Paulo: Cortez Editora, 2014.

SANTOS, Rafael Barbi C. A cultura, o segredo e o índio: diferença e cosmologia entre os Xakriabá de São João das Missões/MG. 2010. Dissertação (Mestrado em em Antropologia Socia) - Universidade Federal de Minas Gerais, Belo Horizonte, MG, 2010.

SANTOS, Rodrigo M. O gê dos gerais: elementos de cartografia para a etno-história do planalto central - contribuição à antropogeografia do cerrado. 2013. Dissertação 
(Mestrado Profissional em Desenvolvimento Sustentável) - Universidade de Brasília, Brasília-DF, 2013.

SILVA, Lucilene Julia. As contribuições do método indutivo intercultural para a construção de uma escola indígena diferenciada: buscando diálogos entre Brasil e México. 2016. Tese (Doutorado em Educação: Conhecimento e Inclusão Social) - Universidade Federal de Minas Gerais, Belo Horizonte, MG, 2016.

SMITH, Linda Tuhiwai. Descolonizando metodologias: pesquisa e povos indígenas. Tradução de Roberto T. Barbosa. Curitiba: Ed. UFPR, 2018.

STENGERS, Isabelle. A proposição cosmopolítica. Revista do Instituto de Estudos Brasileiros, São Paulo, n. 69, p. 442-64. Disponível em: https://doi.org/10.11606/issn.2316-901X. v0i69p442-464. Acesso em: 20 jan. 2018.

\section{Sobre as autoras:}

Ana Maria R. Gomes: Doutora em Educação pela Università di Bologna com pós-doutorado no PPGAS/Museu Nacional (UFRJ) e University of St. Andrews. Professora Titular da Faculdade de Educação da Universidade Federal de Minas Gerais (UFMG). E-mail: anagomes@ufmg.br, ORCID: https://orcid.org/0000-0002-3440-931X

Célia Nunes Corrêa: Doutoranda em Antropologia na Universidade Federal de Minas Gerais (UFMG). Mestre em Desenvolvimento Sustentável junto a Povos e Terras (MESPT/UnB). Professora diplomada no curso de Formação Intercultural para Educadores Indígenas na UFMG. E-mail: celianune7@gmail.com

Shirley Aparecida de Miranda: Pós-doutorado no CES/Universidade de Coimbra. Doutora em Educação pela Universidade Federal de Minas Gerais (UFMG). Professora Associada da Faculdade de Educação da UFMG. E-mail: smiranda@ufmg.br, Orcid: https://orcid.org/0000-0001-8312-2262

Recebido em: 8 de maio de 2020.

Aprovado para publicação em: 30 de novembro de 2020 . 